\title{
The Injured Limb Presents Lower Values in Foot Structure Measurements 6 Years After an Achilles Tendon Rupture
}

\author{
A. Brorsson ${ }^{1}$, U. Sædís Jónsdóttir ${ }^{1}$, D. Nygren ${ }^{2,3}$, N. Larsson ${ }^{3,4}$, R. Tranberg ${ }^{1}$ \\ 1 Department of Orthopaedics, Institute of Clinical Sciences at Sahlgrenska Academy, University of Gothenburg, \\ Gothenburg, Sweden \\ 2 Sportrehab, Sports Medicine Clinic, Gothenburg, Sweden \\ 3 Department of Health and Rehabilitation, Unit of Physiotherapy, Institute of Neuroscience and Physiology at \\ Sahlgrenska Academy, University of Gothenburg, Gothenburg, Sweden \\ ${ }^{4}$ Department of Physiotherapy, Unit of Physiotherapy, Sahlgrenska University Hospital/Mölndal, Gothenburg, \\ Sweden
}

\section{CORRESPONDING AUTHOR:}

\section{Annelie Brorsson}

Department of Orthopaedics

Sahlgrenska University Hospital/Mölndal

Göteborgsvägen 31

43180 Mölndal

Gothenburg, Sweden

E-mail: annelie.brorsson@orthop.gu.se

DOI:

10.32098/mltj.04.2021.12

LEVEL OF EVIDENCE: 2B

\section{SUMMARY}

Background. It is not known if foot structure may change after an Achilles tendon rupture and if a possible change may have an impact on lower limb function.

The primary aim of the study was to explore the difference in foot structure between injured and healthy limb and between two treatment groups, at mean 6 years after an Achilles tendon rupture. A secondary aim was to explore if the differences in foot structure correlated with functional and clinical outcome.

Methods. Ninety patients (15 women) with the mean (SD) age of 49 (9) years were evaluated. They had all been randomized to be treated with $(n=45)$ or without $(\mathrm{n}=45)$ surgery. Foot structure was evaluated with Navicular Drop (Ndrop) and Drift (Ndrift), Longitudinal Arch Angle (LAA) and standing Dorsiflexion with knee straight and bent (DFstraight) and (DFbent). Calf muscle performance was evaluated with Single-leg standing heel-rise test and tendon length with ultrasound. For Patient-reported outcome measurements, Achilles tendon Total Rupture Score (ATRS) and Physical Activity Scale (PAS) were used. Both limbs were evaluated and the limb symmetry index $($ LSI $(\%)=$ injured/healthy $\times 100)$ was calculated.

Results. In all patients, the injured limb demonstrated lower values (injured/healthy) in Ndrift $(6.0 / 6.7 \mathrm{~mm}, \mathrm{p}=0.034)$, Ndrop $(6.6 / 7.4 \mathrm{~mm}, \mathrm{p}=0.32)$ and DFbent $\left(44 / 46^{\circ}, p<0.001\right)$. In the group treated with surgery, there was significant difference between limbs in DFbent $\left(44 / 46^{\circ}, \mathrm{p}=0.002\right)$. In the non-surgically treated group, the injured limb demonstrated significantly lower values in Ndrift (6.0/7.4 $\mathrm{mm}, \mathrm{p}=0.005)$, Ndrop $(6.9 / 8.2 \mathrm{~mm}, \mathrm{p}=0.005)$ and DFbent $\left(44 / 46^{\circ}, \mathrm{p}=0.008\right)$. There was no difference between treatment groups in LSI-values.

Conclusions. An Achilles tendon rupture seems to have an impact on foot structure long time after the injury. There is a need to clarify if the injury influences both feet and if there is a difference between treatment groups.

\section{KEY WORDS}

Achilles tendon rupture; foot structure; long-term follow-up; recovery; rehabilitation. 


\section{BACKGROUND}

The incidence of Achilles tendon ruptures has increased in the last decades and has been reported to be 55/100000 inhabitants in men and 14/100000 inhabitants in women (1). There is evidence that the re-rupture rate is equivalent between patients treated with surgery and patients treated with no surgery if early weightbearing and functional rehabilitation are performed (2). However, other studies have reported a lower re-rupture rate and a better functional outcome in surgically treated patients even if there are other risk factors with surgical treatments such as wound problems and nerve damage (3).

Permanent deficits in calf muscle strength, endurance and heel-rise height are reported several years after an Achilles tendon rupture (4). Therefore, an Achilles tendon rupture may also have a negative impact on gait, running and jumping activities even if these activities also are dependent on strength, coordination and core muscles as well as balance performance (5). However, there are evidence that an Achilles tendon rupture may cause deficits in jumping ability during a drop counter movement jump two years after the injury (6). Moreover, Willy et al. (7) proved that patients with an Achilles tendon rupture had decreased ankle joint power, but increased knee joint power in the injured limb during hopping six years after the injury.

Long term deficits in gait and running after an Achilles tendon rupture have also been reported $(8,9)$. Tengman et al. (8) concluded that a group of patients had shorter step length during walking in both limbs compared to a healthy control group 2-5 years after the injury. Additionally, the patients had lower work both in the ankle and in the knee bilaterally compared to the control group. At mean 6 years after the injury, Jandacka et al. (9) found that during barefoot walking and running, athletes that have had an Achilles tendon rupture showed increased internal knee abduction moments compared with a healthy control group. The deficits in gait and running after an Achilles tendon rupture are for sure due to both changes in muscle strength, ankle range of motion and endurance, but not much is known about what happens to foot posture and foot structure after this injury.

It has been reported that different types of foot structure may have an impact on developing overuse injuries in the lower limb in some individuals (10-13). The medial longitudinal arch in the foot has been described to be low, normal or high and depending on the height, it could cause malalignment such as pes cavus or pes planus (14). Navicular drop and navicular drift are clinical tests that have been used to identify a low or high medial longitudinal arch (15). Navicular drop describes the navicu- lar tuberosity's vertical movement while navicular drift describes the horizonal movement from a non-weight bearing position to a weight bearing position (15). The evaluation of the longitudinal arch angle (LAA) has also been presented as a useful clinical test for evaluating the medial longitudinal arch angle (16). It has been suggested that a low medial longitudinal arch in the foot may lead to an increased risk for pain in the lower $\operatorname{limb}(10,12,13)$. However, to our understanding, there is a lack of knowledge about if and how foot structure may change after an Achilles tendon rupture and if a possible change may have an impact on lower limb function.

Therefore, the primary aim of this study was to evaluate possible difference in foot structure between the injured and the healthy limb and between treatment groups six years after an Achilles tendon rupture. A secondary aim was to explore if the differences in foot structure between limbs correlated with functional and clinical outcome in the lower limb and if there was a difference between treatment groups.

\section{METHODS}

\section{Population}

In total 90 patients were included in the present study. They had originally been included in either of two randomized controlled trials (RCT) where they had been randomized to be treated with or without surgery $(17,18)$. At mean six years after their Achilles tendon rupture, these cohorts participated in two different long-term followup studies where evaluations of foot structure, lower limb function and tendon length were performed $(4,19)$. Inclusion criteria for these long-term follow-ups were that they had been included in one of the above mentioned RCT's and also had participated in the one-year followup. Exclusion criteria were re-rupture, bilateral Achilles tendon ruptures or any other injury in the ankle joint that prevented them to perform the functional evaluations. The demographics of the included patients are presented in table I.

The research protocols (S617-03/307-07/032-09 for the original RCT's and additional applications for the present study: T426-12/058-14) have been approved by the Regional Ethical Review Board in Gothenburg, Sweden. Both oral and written consent were obtained from all participants before recruitment and the study was conducted according to international standards as described by Padulo et al. (20).

For all 90 patients, the same experienced physiotherapist $(\mathrm{AB})$ performed all evaluations. 
Table I. Patient characteristics and group comparisons at mean 6 years after the Achilles tendon rupture.

\begin{tabular}{lllll}
\hline Variables & Total & Surgery & Non surgery & P-Value \\
\hline Age & $\mathrm{N}=90$ & $\mathrm{~N}=45$ & $\mathrm{~N}=45$ & .209 \\
\hline Mean (SD) & $49(9)$ & $50(9)$ & $48(9)$ & 45 \\
\hline Median & 48 & 49 & $34-69$ & \\
\hline Min-Max & $30-69$ & $30-67$ &
\end{tabular}

\begin{tabular}{llll}
\hline Body mass index $(\boldsymbol{B M I})$ & & & \\
\hline Mean $($ SD) & $27.0(3.5)$ & $27.1(3.2)$ & $26.9(3.8)$ \\
\hline Median & 26.3 & 26.2 & 26.4 \\
\hline Min-max & $21.8-44.9$ & $22.3-35.2$ & $21.8-44.9$ \\
\hline & & & \\
\hline Year since injury & & & 684 \\
\hline Mean (SD) & $6.3(1.5)$ & $6.4(1.5)$ & 7 \\
\hline Median & 7 & 7 & $4-9$ \\
\hline Min-max & $4-9$ & $4-9$ & .723 \\
\hline Sex (men/women) & & $36 / 6$ \\
\hline Body
\end{tabular}

Body Mass Index $(\mathrm{BMI})=$ weight $(\mathrm{kg}) /$ height $(\mathrm{m})^{2}$.

\section{Surgical techniques}

Forty-five patients were treated with surgery and 45 patients with non-surgery and all of them had been randomized to be treated either with surgery or without surgery. In all patients treated with surgery, an open surgical technique was used. The same modified Kessler technique (21) was used in all patients but in 11 of the 45 patients, semi-absorbable sutures (No.-2 OrthocordTM, Depuy Mitek, Norwood, MA) were used instead of absorbable 1-0 polydioxanone (PDS) sutures (PDS II, Ethicon, Somerville, New Jersey). In this study, no comparison was performed between the two different sutures.

\section{Foot structure}

Foot structure measurements were performed as described by Barton et al. (10). These measurements have not been proved to be valid for patients with Achilles tendon rupture but have been found to be reliable and sensitive on a group level in patients with patellofemoral pain syndrome (PFPS) (10). Both the intrarater and the interrater reliability were found to be good to excellent (ICC-values between 0.74-0.95 and 0.54-0.93 respectively) with higher values for experienced raters (10).

\section{Navicular drop and drift}

Navicular drop and drift tests are designed to describe how the navicular bone moves from an unloaded position
- with the ankle joint placed in a subtalar joint neutral position - to a weightbearing position where both feet are loaded equally with body weight $(10,15)$. A business card was used to mark how much the navicular bone moved in both directions (figure 1).

The vertical navicular height (VNH) was marked in both positions and navicular drop and drift were calculated from the marks on the business card (10).

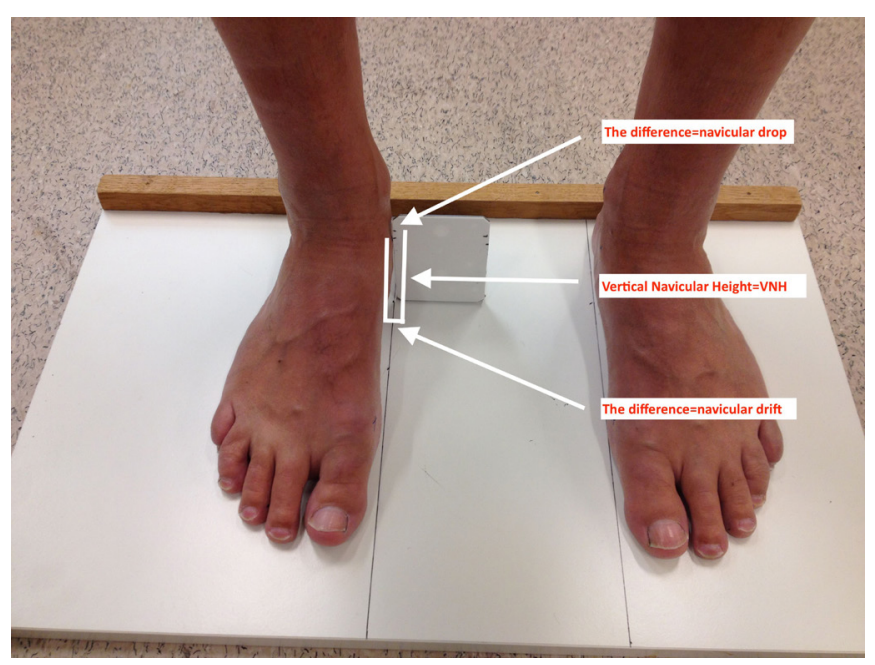

Figure 1. Vertical navicular height and navicular drop and drift. 


\section{Longitudinal Arch Angle (LAA)}

The LAA is the angle formed by the two vectors with the origin on the tip of the navicular bone; one line goes through the medial malleolus and the other through the medial part of the first metatarsal head (16) (figure 2). The LAA was measured with a goniometer.

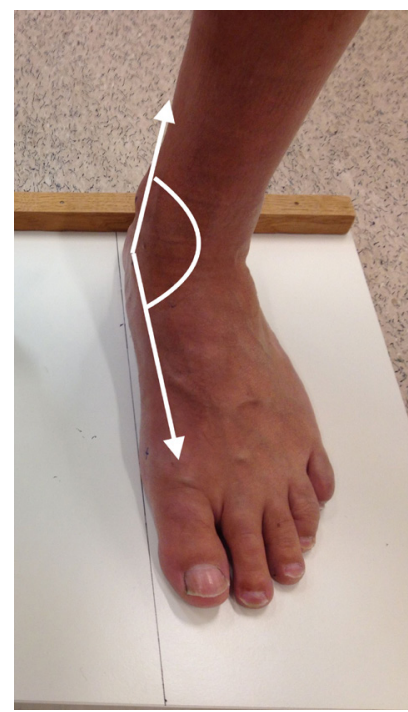

Figure 2. Longitudinal Arch Angle.

\section{Dorsiflexion in the ankle}

The dorsiflexion of the ankle was evaluated in a standing position, both with the knee straight and bent. A digital inclinometer placed on the anterior border of the patient's tibia was used to measure the dorsiflexion in the ankle joint (22) (figure 3).

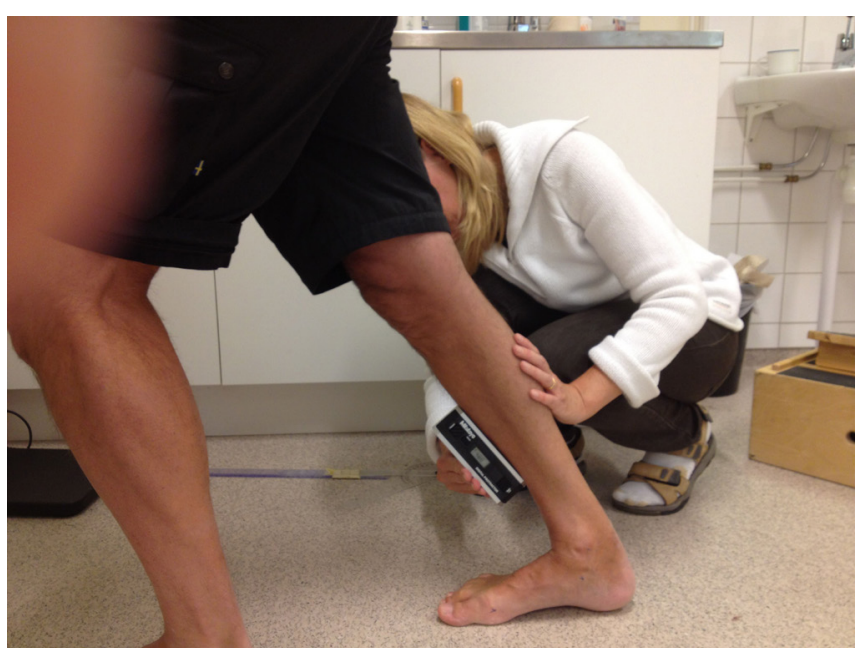

Figure 3. Evaluation of the dorsiflexion in the ankle joint in a standing position with the knee straight.

\section{Single-leg standing heel-rise test}

A single-leg standing heel-rise test was used for evaluating calf muscle endurance. This test has been proved to be reliable and valid for evaluating patients with Achilles tendon ruptures (23). The patients were standing on a box with $10^{\circ}$ incline on one leg and performed as many heel-rises at possible with a straight knee. A linear encoder was attached to the patients' shoe and, during the test, MuscleLab ${ }^{\circledR}$ system (Ergotest Technology, Oslo, Norway) was used to evaluate the performed heel-rise height $(\mathrm{cm})$, number of repetitions (n), and total amount of work (Joule). The pace was set to 30 heel-rises per minute and the test ended either when the patient was unable to keep up the tempo or incapable to perform a heel-rise higher than $2 \mathrm{~cm}$. The healthy leg was evaluated first in all evaluations.

\section{Tendon length}

The Achilles tendon length was evaluated with ultrasound using the extended field of view (Logiq E Ultrasound; GE Healthcare Sweden AB). Both the injured and healthy limb were measured between the calcaneal osteotendinous junction (OTJ) and the gastrocnemius musculotendinous junction (MTJ) as described by Silbernagel et al. (24).

\section{Patient-reported outcome measurements}

The Physical Activity Level was evaluated with Physical Activity Scale (PAS) (25) which is a 6 graded scale from 1-6 where 1 indicates hardly any physical activity and 6 indicates heavy and hard physical exertion several times a week. Achilles tendon Total Rupture Score (ATRS) (26) was used to evaluate patient-reported symptoms and function. ATRS is a reliable and valid score developed specifically for patients with Achilles tendon ruptures and is a widely used score in studies investigating patients with Achilles tendon ruptures. It consists of 10 questions and the maximum score is 100 , which is an indication of no symptoms and full functional recovery.

\section{Statistical analyzes}

No power calculation could be performed since, to our knowledge, foot structure has not been evaluated in patients with Achilles tendon rupture before. Instead, all evaluations were performed by the same experienced physiotherapist (A.B.) and all patients were randomized to treatment with and without surgery.

Shapiro-Wilks test showed that some of the variables were not normally distributed, therefore non-parametric statistics were used. For comparison between limbs, Wilcoxon signed rank 
test was used and for comparison between treatment groups, Mann-Whitney U test was used. Spearman's correlation coefficient was used for exploring if interlimb differences in foot structure correlated with functional and clinical outcome in lower limb.

Level of significance was set to $\mathrm{p} \leq 0.05$.

Limb Symmetry Index (LSI) was used to compare interlimb differences between groups and was calculated as a quote between the injured limb and the healthy limb $\times 100$, expressed as percent $(\%)$.

\section{RESULTS}

\section{Difference in foot-structure between injured and} healthy limb and between treatment groups

Six years after the Achilles tendon rupture, the patients presented lower values in navicular drop and drift, and ankle dorsiflexion with the knee bent in their injured limb compared to the healthy limb (table II). There was no difference between treatment groups but comparison between the healthy limbs showed higher values in the group treated with non-surgery regarding LAA and navicular drop and drift (table II).

\section{Difference in functional and clinical variables between injured and healthy limb and between treatment groups}

The whole population and both treatment groups presented deficits in the injured limb in the functional and clinical variables except for numbers of repetitions in single-leg standing heel-rise test in the group treated with surgery (table III).

\section{Differences in patient reported outcomes (PROMS) between treatment groups}

The group treated with non-surgery reported a higher physical activity level compared to the group treated with surgery (table IV). No other differences were found.

\section{Correlations}

Non-surgery group $(n=45)$

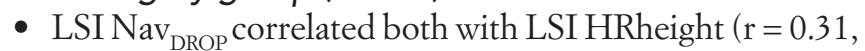
$\mathrm{p}=0.044)$ and LSI DF STRAIGHT $(\mathrm{r}=-0.34, \mathrm{p}=0.023)$.

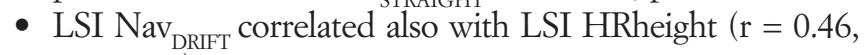
$\mathrm{p}=0.002)$.

\section{DISCUSSION}

The most important finding in this study was that, still six years after the Achilles tendon rupture, the patients presented lower values in foot structure measurements in the injured limb compared to the healthy limb. The group treated with non-surgery presented interlimb differences in more foot structure variables compared to the group treated with surgery. However, there was no differences between treatment groups comparing the LSI-values. Interestingly, it was shown that the group treated with non-surgery had higher foot structure values in their healthy limb compared to the healthy limb in the group treated with surgery. There were no differences in foot structure values in the injured limb between groups.

In the present study, few correlations were found between foot structure and functional or clinical outcome and only in the group treated with non-surgery.

To our knowledge, foot structure has not been explored in patients with Achilles tendon rupture before. Additionally, very little is known about if these patients are at higher risk for other over-use injuries after their rupture. Neal et al. (27) showed limited evidence that a pronated foot posture was a risk factor for developing patellofemoral pain. In the present study, all participants were asked if they had any other injury that kept them from being physically active and in that case, which body part. Nine patients said they had symptoms from their knee, four from the hip/groin, two from the back, three from the shoulder, one from the chest and one from the stomach. However, from this data, it is not possible to draw the conclusion that a change in foot structure is the cause for symptoms from other body parts.

Foot length and gender have been suggested to influence navicular drop (28). In the present study foot length was not evaluated in all patients and therefore not included in the calculations, but for the 66 patients where foot length was evaluated, there was no difference between treatment groups and there was no difference in gender distribution. It has been proved that early weight-bearing and accelerated rehabilitation are favorable after an Achilles tendon rupture (2). Being immobilized for 8 weeks may cause weakness in the intrinsic muscles as well as in the extrinsic muscles in the injured lower leg. In the present study, 66 of the patients were not allowed to weight-bear before the sixth week but they were allowed to actively move their foot in plantarflexion from the second week (17). For 24 of the included patients, they were allowed to weight-bear at once after the injury (18). All patients were exhorted to move their toes several times a day. To not be able to weight-bear on the injured limb may have caused an over-use reaction on the healthy limb but it is unknown if this could have a permanent effect on the foot structure.

In the present study, patients treated with non-surgery had interlimb differences in more foot structure variables than patients treated with surgery. However, the differences were presented in the healthy limb and not in the injured limb. 
Table II. Results in foot structure between healthy and injured limb and between treatment groups. The differences between the injured limbs and the healthy limbs in the two treatment groups are also presented.

\begin{tabular}{|c|c|c|c|c|c|c|c|c|c|c|c|c|}
\hline Variables & 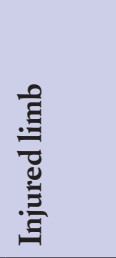 & 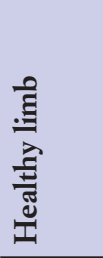 & 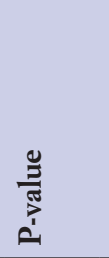 & 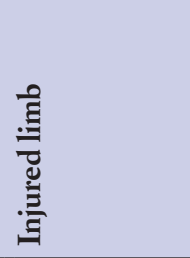 & 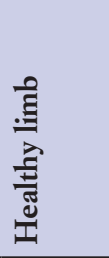 & 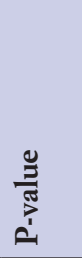 & 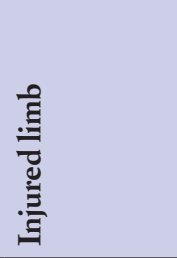 & 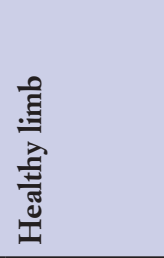 & 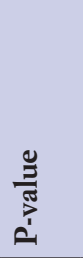 & 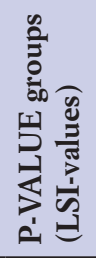 & 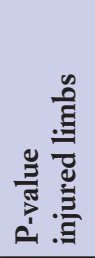 & 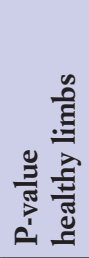 \\
\hline & Total & & & Surgery & & & Non-surgery & & & & & \\
\hline LAA & $\mathrm{n}=90$ & $\mathrm{n}=90$ & & $\mathrm{n}=45$ & $\mathrm{n}=45$ & & $\mathrm{n}=45$ & $\mathrm{n}=45$ & & & & \\
\hline $\begin{array}{l}\text { Mean } \\
\text { (SD) }\end{array}$ & $\begin{array}{l}142.6 \\
(13.4)\end{array}$ & $\begin{array}{l}143.7 \\
(12.5)\end{array}$ & .071 & $138.8(16.6)$ & $\begin{array}{l}139.6 \\
(14.2) \\
\end{array}$ & .396 & $146.4(7.7)$ & $147.9(8.9)$ & .093 & .818 & .060 & .016 \\
\hline Median & 144 & 145.5 & & 142 & 144 & & 146 & 148 & & & & \\
\hline $\begin{array}{l}\text { Min } \\
\text { Max }\end{array}$ & $\begin{array}{l}100 \\
168 \\
\end{array}$ & $\begin{array}{l}98 \\
168 \\
\end{array}$ & & $\begin{array}{l}100 \\
162 \\
\end{array}$ & $\begin{array}{l}98 \\
160 \\
\end{array}$ & & $\begin{array}{l}136 \\
168 \\
\end{array}$ & $\begin{array}{l}128 \\
168 \\
\end{array}$ & & & & \\
\hline NavDrift (mm) & $\mathrm{n}=90$ & $\mathrm{n}=90$ & & $\mathrm{n}=45$ & $\mathrm{n}=45$ & & $\mathrm{n}=45$ & $\mathrm{n}=45$ & & & & \\
\hline $\begin{array}{l}\begin{array}{l}\text { Mean } \\
(\mathrm{SD})\end{array} \\
\end{array}$ & $\begin{array}{l}6.0 \\
(3.2) \\
\end{array}$ & $\begin{array}{l}6.7 \\
(3.4) \\
\end{array}$ & .034 & $\begin{array}{l}6 \\
(3.3) \\
\end{array}$ & $\begin{array}{l}6 \\
(3.7) \\
\end{array}$ & .946 & $\begin{array}{l}6.0 \\
(3.2) \\
\end{array}$ & $\begin{array}{l}7.4 \\
(3) \\
\end{array}$ & .005 & .100 & .807 & .044 \\
\hline Median & 5 & 6 & & 5 & 5 & & 6 & 8 & & & & \\
\hline Min & 0 & 0 & & 1 & 0 & & 0 & 2 & & & & \\
\hline Max & 17 & 14 & & 17 & 14 & & 14 & 14 & & & & \\
\hline NavDrop (mm) & $\mathrm{n}=90$ & $\mathrm{n}=90$ & & $\mathrm{n}=45$ & $\mathrm{n}=45$ & & $\mathrm{n}=45$ & $\mathrm{n}=45$ & & & & \\
\hline $\begin{array}{l}\begin{array}{l}\text { Mean } \\
(\mathrm{SD})\end{array} \\
\end{array}$ & $\begin{array}{l}6.6 \\
(3.4) \\
\end{array}$ & \begin{tabular}{|l|}
7.4 \\
$(3.6)$ \\
\end{tabular} & .032 & $\begin{array}{l}6.4 \\
(3.9) \\
\end{array}$ & $\begin{array}{l}6.6 \\
(3.9) \\
\end{array}$ & .850 & $\begin{array}{l}6.9 \\
(3.4) \\
\end{array}$ & $\begin{array}{l}8.2 \\
(3.2) \\
\end{array}$ & .005 & .156 & .383 & .019 \\
\hline Median & 6 & 7.5 & & 6 & 6 & & 6 & 9 & & & & \\
\hline Min & 0 & 0 & & 1 & 0 & & 0 & 2 & & & & \\
\hline Max & 17 & 17 & & 17 & 17 & & 17 & 15 & & & & \\
\hline DFBent $\left({ }^{\circ}\right)$ & $\mathrm{n}=90$ & $\mathrm{n}=90$ & & $\mathrm{n}=45$ & $\mathrm{n}=45$ & & $\mathrm{n}=45$ & $\mathrm{n}=45$ & & & & \\
\hline $\begin{array}{l}\begin{array}{l}\text { Mean } \\
\text { (SD) }\end{array} \\
\end{array}$ & $\begin{array}{l}44 \\
(6.6) \\
\end{array}$ & $\begin{array}{l}46 \\
(6.6) \\
\end{array}$ & $<.001$ & $\begin{array}{l}44 \\
(6.4) \\
\end{array}$ & $\begin{array}{l}46 \\
(6.2) \\
\end{array}$ & .002 & $\begin{array}{l}44 \\
(6.8) \\
\end{array}$ & $\begin{array}{l}46 \\
(7.0) \\
\end{array}$ & .008 & .881 & .945 & .725 \\
\hline Median & 44 & 46 & & 44 & 46 & & 44 & 46 & & & & \\
\hline Min & 30 & 33 & & 30 & 36 & & 32 & 33 & & & & \\
\hline Max & 65 & 65 & & 58 & 62 & & 65 & 65 & & & & \\
\hline DFStraight $\left({ }^{\circ}\right)$ & $\mathrm{n}=90$ & $\mathrm{n}=90$ & & $\mathrm{n}=45$ & $\mathrm{n}=45$ & & $\mathrm{n}=45$ & $\mathrm{n}=45$ & & & & \\
\hline $\begin{array}{l}\text { Mean } \\
\text { (SD) }\end{array}$ & $\begin{array}{l}39 \\
(6) \\
\end{array}$ & $\begin{array}{l}40 \\
(6) \\
\end{array}$ & .336 & $\begin{array}{l}39 \\
(7) \\
\end{array}$ & $\begin{array}{l}40 \\
(7) \\
\end{array}$ & .368 & $\begin{array}{l}40 \\
(6)\end{array}$ & $\begin{array}{l}40 \\
(7)\end{array}$ & .678 & .765 & .487 & .961 \\
\hline Median & 38 & 40 & & 38 & 40 & & 39 & 40 & & & & \\
\hline Min & 25 & 27 & & 27 & 29 & & 25 & 27 & & & & \\
\hline Max & 61 & 55 & & 55 & 55 & & 61 & 55 & & & & \\
\hline
\end{tabular}

Significant differences are presented in bold. 
Table III. Results in functional and clinical variables between healthy and injured limb and between treatment groups.

The differences between the injured limbs and the healthy limbs in the two treatment groups are also presented.

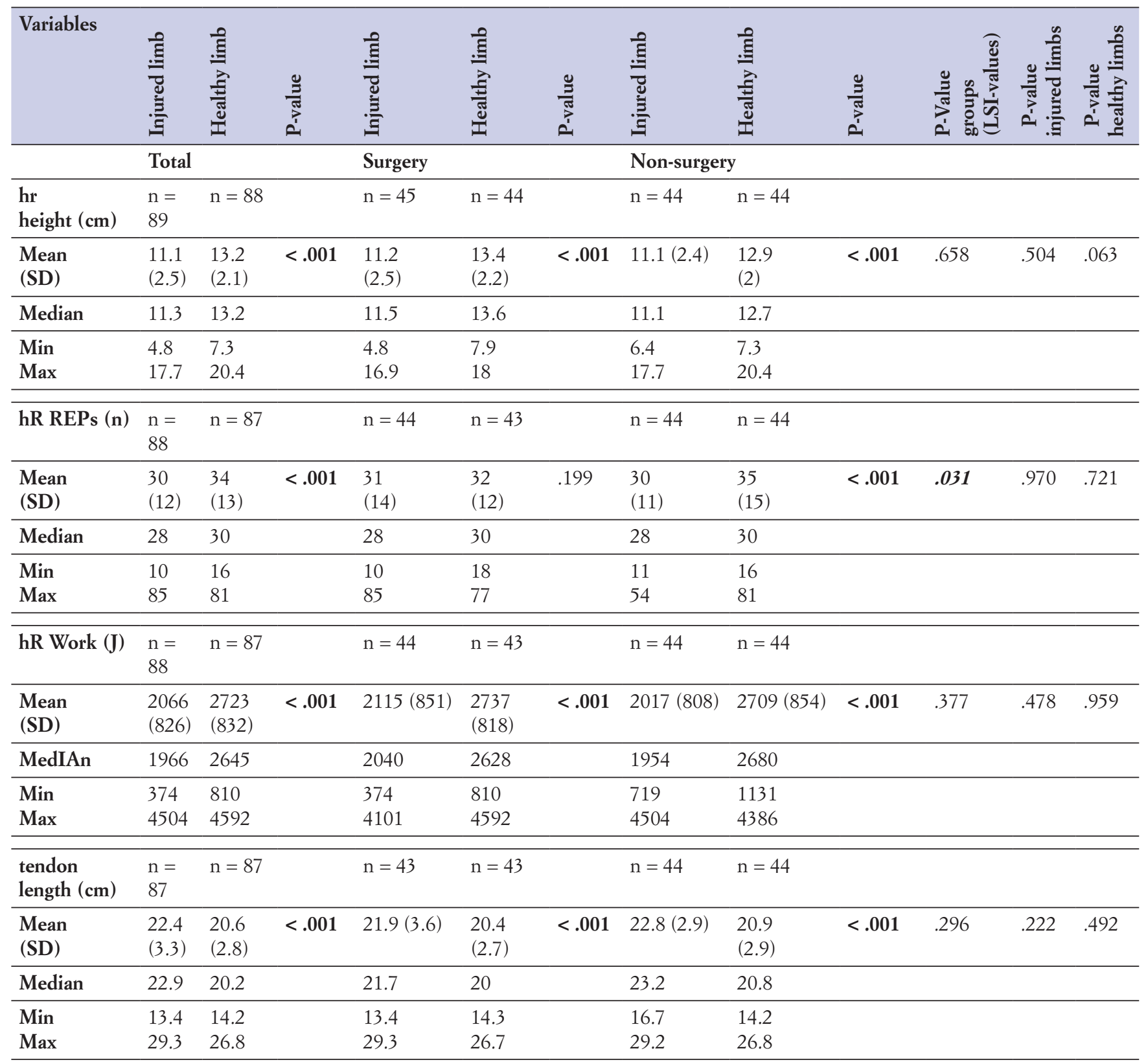

Significant differences are presented in bold. 
Table IV. Results in patient reported outcomes (PROMS) in the whole population and in the two treatment groups.

\begin{tabular}{lllll}
\hline PROMS & $\begin{array}{l}\text { TOTAL } \\
(\mathrm{n}=90)\end{array}$ & $\begin{array}{l}\text { SURGERY } \\
(\mathrm{n}=45)\end{array}$ & $\begin{array}{l}\text { NON- SURGERY } \\
(\mathrm{n}=45)\end{array}$ & P-VALUE \\
Atrs & & & & \\
Mean (SD) & $90(16)$ & $90(17.7)$ & $89(14)$ & .297 \\
Median & 95 & 95 & 94 & \\
Min-Max & $0-100$ & $0-100$ & $22-100$ & \\
\hline Pas & & & & .044 \\
Mean (SD) & $3.9(1.1)$ & $3.7(1.1)$ & 4 & \\
Median & 4.0 & 3.0 & $2-6$ & \\
Min-Max & $2-6$ & $2-6$ & & \\
\hline
\end{tabular}

Significant differences are presented in bold.

Headlee et al. (29) found that fatigue in the intrinsic muscles of the foot, increased the pronation in healthy individuals. The reason for this could be that the intrinsic muscles support the medial longitudinal arch in the foot (29). It is unknown if treatment with non-surgery increase the load on the healthy foot compared to treatment with surgery and there is a need to further explore what impact treatment have both in the injured and the healthy limb after an Achilles tendon rupture.

It is possible that an acquired low medial longitudinal arch could develop over years and that a change in movement pattern could lead to a low medial longitudinal arch. Furthermore, this could lead to a decreased ability in heelrise height, which may be a possible explanation for the correlations between navicular drop and drift and heel-rise height in the present study (30). It has also been proved that persons with a low longitudinal arch together with a mobile foot are at greater risk for injuries since it would lead to increased biomechanical demands during walking (11). However, Okamura et al. (31) proved that activation of the intrinsic foot muscles had an impact on the medial longitudinal arch during gait and standing in subjects who were flat-footed. Therefore, it is important to guide the patients with Achilles tendon ruptures in exercises designed for strengthening the foot muscles both in the injured and uninjured foot.

A limitation in this study is the lack of comparison in foot structure in healthy subjects. Moreover, it is not known what values the patients had in foot structure before the injury. Furthermore, there is a lack of studies comparing foot structure between the right and left foot in healthy subjects. Nevertheless, in a large study, navicular drop was evaluated in 500 healthy Indian men and women between 18-21 years. In this study, no difference was found between the right and left foot (median (IQR)); $6 \mathrm{~mm}(4-9) / 6 \mathrm{~mm}$ (4-9), $\mathrm{p}=0.200$ (32). This is the same median value as in the present study except for the healthy limb in patients treated with non-surgery.

There was also a difference in physical activity level between treatment groups which could be a limitation in the present study. The patients treated with surgery scored at median of 3 and patients treated with non-surgery scored at median of 4 on the 6-level questionnaire, PAS (25). Level 3 means "Light physical exercise around 2-4 hours a week, e.g., walks, fishing, dancing, normal gardening, including walks to and from shops" while level 4 means "Moderate exercise 1-2 hours a week, e.g., jogging, swimming, gymnastics, heavy gardening, home repairs or easy physical activities more than 4 hours a week". It cannot be concluded if this difference may have an impact on foot structure in the present study since physical activity also may change over time.

The reliability in navicular drop and drift have been found to be weak to moderate but higher reliability for experienced evaluators (10). However, in the present study, all foot structure measurements were performed by the same, experienced physiotherapist.

In the present study, foot structure evaluation was only performed once and that was several years after the injury. This is a limitation since evaluation over time would have given us more information how foot structure may change after the injury. It is also unknown if the two different sutures used in the surgically treated patients could have any impact on foot structure. Taken together, further studies are needed, mainly focusing on possible foot structure changes after an Achilles tendon rupture and of how foot structure is affected by different demanding activities such as running and jumping.

\section{CONCLUSIONS}

An Achilles tendon rupture seems to have an impact on foot 
structure long time after the injury. There is a need to clarify if the injury influences both feet and if there is a difference between treatment groups.

\section{Highlights}

An Achilles tendon rupture seem to have an impact on foot structure.

Non-surgically treated presented higher foot structure values in the healthy limb.

Foot structure values did not differ between groups in the injured limb.

\section{REFERENCES}

1. Huttunen TT, Kannus P, Rolf C, Fellander-Tsai L, Mattila VM. Acute achilles tendon ruptures: incidence of injury and surgery in Sweden between 2001 and 2012. Am J Sports Med 2014;42(10):2419-23.

2. Zhang H, Tang H, He Q, et al. Surgical Versus Conservative Intervention for Acute Achilles Tendon Rupture: A PRISMA-Compliant Systematic Review of Overlapping Meta-Analyses. Medicine (Baltimore) 2015;94(45):e1951.

3. Ochen Y, Beks RB, van Heijl M, et al. Operative treatment versus nonoperative treatment of Achilles tendon ruptures: systematic review and meta-analysis. BMJ 2019;364:k5120.

4. Brorsson A, Gravare Silbernagel K, Olsson N, Nilsson Helander K. Calf Muscle Performance Deficits Remain 7 Years After an Achilles Tendon Rupture. Am J Sports Med 2018;46(2):470-7.

5. Kollias I, Hatzitaki V, Papaiakovou G, Giatsis G. Using principal components analysis to identify individual differences in vertical jump performance. Res Q Exerc Sport 2001;72(1):63-7.

6. Olsson N, Nilsson-Helander K, Karlsson J, Eriksson BI, Thomee R, Faxen E, et al. Major functional deficits persist 2 years after acute Achilles tendon rupture. Knee Surg Sports Traumatol Arthrosc 2011;19(8):1385-93.

7. Willy RW, Brorsson A, Powell HC, Willson JD, Tranberg R, Gravare Silbernagel K. Elevated Knee Joint Kinetics and Reduced Ankle Kinetics Are Present During Jogging and Hopping After Achilles Tendon Ruptures. Am J Sports Med 2017;45(5):1124-33.

8. Tengman T, Riad J. Three-Dimensional Gait Analysis Following Achilles Tendon Rupture With Nonsurgical Treatment Reveals Long-Term Deficiencies in Muscle Strength and Function. Orthop J Sports Med 2013;1(4):2325967113504734.

9. Jandacka D, Plesek J, Skypala J, Uchytil J, Silvernail JF, Hamill J. Knee Joint Kinematics and Kinetics During Walking and Running After Surgical Achilles Tendon Repair. Orthop J Sports Med 2018;6(6):2325967118779862.

10. Barton CJ, Bonanno D, Levinger P, Menz HB. Foot and ankle characteristics in patellofemoral pain syndrome: a case control and reliability study. J Orthop Sports Phys Ther 2010;40(5):286-96.

\section{ACKNOWLEDGEMENTS}

The authors want to thank Lotta Falkheden Henning and Katarina Nilsson Helander for help with data collection. This study was partly funded by grants from the Swedish Research Council for Sports Science (CIF), Sweden, the Local Research and Development Board for Gothenburg and Södra Bohuslän, Sweden and the Local Research and Development Council of Halland, Sweden.

\section{CONFLICT OF INTERESTS}

The authors declare that they have no conflict of interests.

11. Maharaj JN, Cresswell AG, Lichtwark GA. Foot structure is significantly associated to subtalar joint kinetics and mechanical energetics. Gait Posture 2017;58:159-65.

12. Ribeiro AP, Trombini-Souza F, Tessutti V, Rodrigues Lima F, Sacco Ide C, João SM. Rearfoot alignment and medial longitudinal arch configurations of runners with symptoms and histories of plantar fasciitis. Clinics (Sao Paulo) 2011;66(6):1027-33.

13. Williams DS 3rd, McClay IS, Hamill J. Arch structure and injury patterns in runners. Clin Biomech (Bristol, Avon) 2001;16(4):341-7.

14. Franco AH. Pes cavus and pes planus. Analyses and treatment. Physical therapy 1987;67(5):688-94.

15. Menz HB. Alternative techniques for the clinical assessment of foot pronation. J Am Podiatr Med Assoc 1998;88(3):119-29.

16. McPoil TG, Cornwall MW. Use of the longitudinal arch angle to predict dynamic foot posture in walking. J Am Podiatr Med Assoc 2005;95(2):114-20.

17. Nilsson-Helander K, Silbernagel K, Thomee R, et al. Acute achilles tendon rupture: a randomized, controlled study comparing surgical and nonsurgical treatments using validated outcome measures. Am J Sports Med 2010;38(11):2186-93.

18. Olsson N, Silbernagel KG, Eriksson BI, et al. Stable surgical repair with accelerated rehabilitation versus nonsurgical treatment for acute Achilles tendon ruptures: a randomized controlled study. Am J Sports Med 2013;41(12):2867-76.

19. Brorsson A, Willy RW, Tranberg R, Gravare Silbernagel K. HeelRise Height Deficit 1 Year After Achilles Tendon Rupture Relates to Changes in Ankle Biomechanics 6 Years After Injury. Am J Sports Med 2017;45(13):3060-8.

20. Padulo J, Oliva F, Frizziero A, Maffulli N. Basic principles and recommendations in clinical and field Science Research: 2018 update. Muscles Ligaments Tendons J 2018;8(3):305-7.

21. Kessler I. The "grasping" technique for tendon repair. Hand 1973;5(3):253-5.

22. Munteanu SE, Strawhorn AB, Landorf KB, Bird AR, Murley GS. A weightbearing technique for the measurement of ankle joint dorsiflexion with the knee extended is reliable. J Sci Med Sport 2009;12(1):54-9.

23. Silbernagel KG, Nilsson-Helander K, Thomee R, Eriksson BI, Karlsson J. A new measurement of heel-rise endurance with the ability to detect functional deficits in patients with Achil- 
les tendon rupture. Knee Surg Sports Traumatol Arthrosc 2010;18(2):258-64.

24. Silbernagel KG, Shelley K, Powell S, Varrecchia S. Extended field of view ultrasound imaging to evaluate Achilles tendon length and thickness: a reliability and validity study. Muscles, Ligaments and Tendons J 2016;6(1):104-10.

25. Grimby G. Physical activity and muscle training in the elderly. Acta Med Scand Suppl 1986;711:233-7.

26. Nilsson-Helander K, Thomee R, Silbernagel KG, et al. The Achilles tendon Total Rupture Score (ATRS): development and validation. Am J Sports Med 2007;35(3):421-6.

27. Neal BS, Griffiths IB, Dowling GJ, et al. Foot posture as a risk factor for lower limb overuse injury: a systematic review and meta-analysis. J Foot Ankle Res 2014;7(1):55.

28. Nielsen RG, Rathleff MS, Simonsen OH, Langberg H. Determination of normal values for navicular drop during walking: a new model correcting for foot length and gender. J Foot Ankle Res 2009;2:12.

29. Headlee DL, Leonard JL, Hart JM, Ingersoll CD, Hertel J. Fatigue of the plantar intrinsic foot muscles increases navicular drop. J Electromyogr Kinesiol 2008;18(3):420-5.

30. Chimenti RL, Tome J, Hillin CD, Flemister AS, Houck J. Adult-acquired flatfoot deformity and age-related differences in foot and ankle kinematics during the single-limb heel-rise test. J Orthop Sports Phys Ther 2014;44(4):283-90.

31. Okamura K, Kanai S, Fukuda K, Tanaka S, Ono T, Oki S. The effect of additional activation of the plantar intrinsic foot muscles on foot kinematics in flat-footed subjects. Foot (Edinb) 2019;38:19-23.

32. Aenumulapalli A, Kulkarni MM, Gandotra AR. Prevalence of Flexible Flat Foot in Adults: A Cross-sectional Study. J Clin Diagn Res 2017;11(6):Ac17-ac20. 